\title{
The dogmatist, Moore's proof and transmission failure
}

\author{
Luca Moretti \\ University of Aberdeen \\ 1.moretti@abdn.ac.uk
}

\begin{abstract}
According to Jim Pryor's dogmatism, if you have an experience as if $P$, you acquire immediate prima facie justification for believing $P$. Pryor contends that dogmatism validates Moore's infamous proof of a material world. Against Pryor, I argue that if dogmatism is true, Moore's proof turns out to be non-transmissive of justification according to one of the senses of non-transmissivity defined by Crispin Wright. This type of non-transmissivity doesn't deprive dogmatism of its apparent antisceptical bite.
\end{abstract}

Keywords: dogmatism, Moore's proof, immediate justification, direct justification, transmission failure.

According to Pryor (2000, 2004)'s dogmatism,

(DOGMA) If one has an experience as if $P$, one acquires immediate prima facie justification for believing $P$.

Immediate prima facie justification for believing a proposition $P$ is defeasible justification for $P$ that is not based on-not even partly-independent justification for anything else (cf. 2000: 533).

(DOGMA) is about propositional, rather than doxastic, justification (cf. 521). ${ }^{1}$ Hence

'justification' in (DOGMA), and everywhere in this article, means propositional justification.

According to (DOGMA), if you have an experience as if, say, there is a plump crimson tomato here, you acquire prima facie justification for believing that there is a plump crimson tomato here that is not based on independent justification for anything else-e.g. on justification for believing that your perceptions are reliable. I present some of Pryor's reasons in support of (DOGMA) below. Note meanwhile that (DOGMA) looks natural and intuitive. (DOGMA) is also philosophically appealing because it seems capable of forming the grounds of (fallible) foundationalism, as it puts an end to the regress of justified beliefs in the search for a basis for our beliefs' justification.

\footnotetext{
1 A subject has propositional justification for a proposition $P$ just in case $P$ is epistemically worthy of being believed by her whether or not she believes $P$ for the right reason or at all.
} 
This paper aims to shield dogmatism from a possible criticism. Pryor (2004: 359-362)

contends that (DOGMA) validates Moore's proof of a material world and he seems to see this as an antisceptical virtue of dogmatism. Since Moore's proof is widely and persistently regarded as flawed, one might fear that if the dogmatist were actually committed to accepting Moore's proof as cogent, this would be perceived as a problem rather than a virtue of dogmatism. I will not endorse dogmatism in this paper. I will confine myself to arguing that if dogmatism is true, then Moore's proof is actually flawed because it is non-transmissive of justification in one of the senses of nontransmissivity described in Wright (2002). Remarkably, this type of non-transmissivity doesn't deprive dogmatism of the antisceptical bite that Pryor thinks it has.

A popular version of the sceptical argument states that:

(SCEPTIC) Since you cannot have justification for believing that there is a material world (i.e. something material), you cannot have justification for believing that there is any specific material thing-for instance a hand-when you have an experience as if there is such a thing.

Moore (1939)'s proof responds to (SCEPTIC) by overturning it as follows:

(MOORE) (H) Here is a hand.

Therefore:

$(W)$ There is a material world.

Here your experience as if there is a hand $(O)$ is supposed to give you justification for believing $H$. If (MOORE) is effective, once you have this justification and realise that $H$ entails $W$, you thereby have justification for believing $W^{2}$

Many epistemologists feel that (MOORE) is epistemically flawed (e.g. circular or questionbegging). Pryor (2004) insists that (MOORE) isn't flawed. If you have $O$-according to Pryor-you acquire immediate justification for $H$. Once you have this justification and realise that $H$ entails $W$, you thereby acquire justification for $W$ (cf. 351). Pryor suggests that the sensed deficiency of (MOORE) reduces to the fact that (MOORE) cannot resolve antecedent doubt about its conclusion.

\footnotetext{
2 I'm following Pryor (2004) and Wright (2002)'s interpretation.
} 
Suppose you doubt $W$. Accordingly, (given what $W$ says) you are rationally required to doubt that $O$ supplies justification for $H$. Thus, your going through (MOORE) cannot dispel your doubt about $W$. Pryor takes this deficiency to be a dialectical limitation of (MOORE)-one restraining its possible uses-rather than an epistemic or structural flaw of it (cf. 366-370).

Wright (2002) has defined some conceptual tools that can help the dogmatist explain why (MOORE) is epistemically flawed. Let's first distinguish between closure of justification and transmission of justification. A basic formulation of the closure principle (sufficient for our purposes) says that, for any deductive argument from $P$ to $Q$, if one has justification for believing $P$ and knows that $P$ entails $Q$, one has justification for believing $Q$. Suppose one is given evidence $E$ in support of $P$. Wright says that one's justification for believing $P$ depending on $E$ transmits across the entailment from $P$ to $Q$ just in case: (i) one actually has justification for believing $P$ from $E$, (ii) one knows that $P$ entails $Q$, and (iii) one has a justification for believing $Q$ just in virtue of the satisfaction of (i) and (ii) (cf. 2002: 332). Whereas closure has been seldom questioned in epistemology, it is acknowledged that transmission sometimes fails. Interesting cases of transmission failure are those in which (i) and (ii) are satisfied but (iii) isn't. In these cases one has justification for believing $Q$ (provided that closure holds true) but not in virtue of the satisfaction of (i) and (ii). Here is an example from Wright (2003: 59). Imagine you are informed that Jessica and Jocelyn are indistinguishable twins, and consider this argument:

(TWINS) $J$. This girl is Jessica.

Therefore:

$N$. This girl is not Jocelyn.

Suppose evidence for $J$ is your learning that $(L)$ this girl looks just like Jessica. Given your background information, $L$ can give you justification for believing $J$ only if you have independent justification for believing $N$ in the first instance. Suppose you actually have independent justification for believing $N$. As you learn $L$, you also have justification for believing $J$. Furthermore, you are certainly aware that $J$ entails $N$. Yet it is intuitive that in this epistemic setting 
you cannot have justification for $N$ in virtue of your justification for believing $J$ depending on $L$ and your knowledge that $J$ entails $N$.

Following Moretti and Piazza (2013: $\S 3.1)$, let's say that a deductive argument from $P$ to $Q$ is non-transmissive of justification depending on $E$ for $P$ across the entailment just in case condition (iii) couldn't be satisfied even if conditions (i) and (ii) were both satisfied. Being non-transmissive is a different property from being a failure of transmission. Any non-transmissive argument is epistemically defective in the sense that it is structurally incapable of conveying justification to its conclusion even if its premise is justified by the relevant evidence and the conclusion is known to follow from the premise. Wright (2002) has individuated two conditions individually sufficient for non-transmissivity of justification, which can be formulated as follows:

(FAIL1) $E$ gives one justification for believing $P$ only if this justification is based on one's independent justification for believing $Q$. (Cf. 332) ${ }^{3}$

(FAIL2) E supplies direct justification for believing $Q$. (Cf. 334-335)

Any deductive argument from $P$ to $Q$ satisfying either condition relative to $E$ is non-transmissive of one's justification for $P$ depending on $E$. I clarify (FAIL2)'s content and workings below. An explanation of (FAIL1)'s functioning is given in Moretti and Piazza (2013: §3.2). Wright (2002) contends that (MOORE) satisfies (FAIL1) relative to $O$ because $O$ gives one justification for $H$ only to the extent that this justification is based on one's independent justification for $W$. (MOORE) is thus non-transmissive of one's justification for $H$ depending on $O$. The dogmatist cannot accept this diagnosis because it is incompatible with the thesis that $O$ provides immediate justification for $H$ (cf. Pryor 2004: 356). Nevertheless, it appears to me that if dogmatism is true, (MOORE) proves non-transmissive because it satisfies (FAIL2).

Consider any deductive argument from $P$ to $Q$ that meets (FAIL2) relative to $E$. Saying that $E$ gives one direct justification for believing $Q$ is saying that $E$ gives one justification for believing $Q$ independently (or not in virtue) of one having justification for believing $P$ from $E$ and knowing that

\footnotetext{
3 This seems to be Pryor (2004)'s interpretation of Wright's condition.
} 
$P$ entails $Q$ (cf. Wright 2002: 334). Clearly, any argument of this type is such that (iii) couldn't be satisfied even if (i) and (ii) were satisfied. Thus any such argument is non-transmissive of one's justification for $P$ depending on $E$. Here is an example by Wright (cf. 333):

(SOCCER) G. Jones has just scored a goal.

Therefore:

$S$. A game of soccer is taking place.

Suppose evidence for $G$ is your learning that $(B)$ Jones has kicked the ball between the white posts and events typically accompanying soccer goals have happened alongside (e.g. the team mates' congratulations, the referee's response, etc.). On the background assumption that it is very unlikely that $B$ is true unless $S$ is true, $B$ gives you justification for believing both $G$ and $S$. This looks like a case in which $B$ gives you direct justification for believing $S$. To see this, consider that if the justification that you have from $B$ for $S$ were one acquired by you in virtue of your having justification from $B$ for $G$ and knowing that $G$ entails $S$, it would presumably be true that hadn't you had justification from $B$ for $G$, you wouldn't have had justification for $S$. But this conditional looks false on standard counterfactual semantics because in closest possible worlds (to the imagined actual world) its antecedent is true and its consequent false. Take for instance a world in which, just before learning $B$, you learn that a referee's assistant has raised his flag signalling Jones' off side. Here $B$ no longer give you justification for $G$ and yet it still gives you justification for believing $S$. (Cf.: 334-335).

Wright agrees that (FAIL2) illuminates why (SOCCER) is non-transmissive ${ }^{4}$ but he denies that (FAIL2) could also explain why (MOORE) is non-transmissive. Wright concedes that $O$ would give you direct justification for $W$ if you had independent justification for believing that $(K)$ it is very unlikely for people to experience $O$ unless $W$ is true. But he suggests that in the dialectic setting of responding to the sceptic-the one surrounding the use of (MOORE)-you cannot take yourself to have justification for believing $K$ (cf. 337). Whether or not Wright's suggestion is correct, it seems

\footnotetext{
${ }^{4}$ (SOCCER) also satisfies (FAIL1), thus its non-transmissivity is independently explained by the satisfaction of either condition (cf. Wright 2002: 333-335).
} 
to me that you don't necessarily require independent justification for $K$ to acquire from $O$ direct justification for $W$. Suppose $O$ could give you direct justification for $W$ coinciding with immediate justification for it. Since immediate justification is not based on independent justification for anything else, you could very plausibly have it even if you had no independent justification for $K{ }^{5}$

I will now argue that if dogmatism is true, $O$ gives you immediate justification for $W$ that also qualifies as direct justification for $W$. To defend (DOGMA), Pryor adduces the popular thesis in current philosophy of mind that our experiences are often provided with propositional contents, where these contents 'are not about sense data or the character of our experiences. They are about manifest observable properties of objects in the world' (Pryor 2000: 539). According to this view, in other words, our experiences are typically about things represented as being non-mental or material. ${ }^{6}$ Pryor maintains that an experience with propositional content $P$ can prima facie justify belief in $P$ because of its assertive phenomenology characterised by 'the feeling of seeming to ascertain that $[P]$ is true' (Pryor 2004: 357. Cf. also Pryor 2000: 547, n37). It is the assertive phenomenology of experience that provides the subject with immediate defeasible justification for believing the experience's content (cf. Pryor 2000: 538-539 and 2004: 357). It appears to me that if this is true, any subject who has an experience with content $P$ should have immediate justification for believing $P$ as well as any proposition constituting a part of that content.

Suppose $T$ is the proposition that there is a tomato. It is implausible that you could have an experience with just $T$ as its content. For experiences about things in the world are typically richer than $T$. (This is so even if we set aside the contentious issue of non-conceptual content.) If you experience as if there is a tomato, you will have the experience as if there is a specific tomato provided with distinctive physical features. Suppose, therefore, that the actual content of your experience is the complex proposition that $(C)$ there is a roughly spherical, small, vermilion... tomato in the middle of the whitish scenery before you. In this case, if you concentrate on the

\footnotetext{
5 A concern might be that your having independent justification for $K$ could turn out to be a necessary though nonbasing condition for your having immediate justification for $W$ from $O$. (Examples of conditions of this type are in Silins 2007.) But I can see no argument for this conclusion.

6 This doesn't beg the question against the sceptic because the contents of experience could be about what is nonexistent.
} 
content of your experience as a whole, you will have the feeling of ascertaining the truth of $C$. But if you turn your attention to parts of the content of your experience, you will have the feeling of ascertaining the truth of more elementary propositions constituting components of $C$-for instance $T$, or the proposition that $\left(T^{*}\right)$ there is something roughly spherical before you. Consequently, if the phenomenology of seeming to ascertain the truth of a given proposition provides you with immediate justification for believing that proposition, the same experience that gives you immediate justification for believing $C$ should also give you immediate justification for believing propositions like $T$ and $T^{*}$ constituting parts of $C^{7}$

The dogmatist appears thus committed to maintaining that your experience can give you immediate justification for a proposition $P$ even if your experience's content is richer than and inclusive of $P$. A way to render this commitment explicit is accompanying (DOGMA) with auxiliary principles such as this:

(DOGMA*) If you have an experience as if there is an $x$ that is among other things $F$, you have immediate prima facie justification for believing that there is an $x$ that is $F$.

Pryor's analysis of (MOORE) seems to rely on (DOGMA*)-or a similar principle-rather than (DOGMA). For it is implausible that your experience $O$, which is meant to immediately justify $H$, could have just $H$ as its content. If you experience as if there is a hand, you will experience as if there is a specific hand with distinctive physical features. So $H$ will just be a fragment of $O$ 's whole content. By appealing to (DOGMA*), the dogmatist can substantiate the claim that if you have the experience as if there is, say, a flesh-coloured, small, square... hand in the middle of the whitish scenery before you, you have immediate prima facie justification for believing that $(H)$ there is a hand.

(DOGMA*) also enables the dogmatist to claim that $O$ gives you immediate justification for believing that $(W)$ there is a material world. Note first that since $H$ entails $W$ in (MOORE), 'hand'

\footnotetext{
${ }^{7}$ Pryor (2000: 519) stresses that you don't need to be aware of your actual experience to have justification for its content-it is sufficient that you can be so. Accordingly, you don't need to turn your attention to parts of your experience's content to have justification for the correlated propositions-it is sufficient that you can do so.
} 
in $H$ must mean material hand. Accordingly, when the dogmatist claims that $O$ gives you immediate justification for believing $H$, she must be meaning that $O$ gives you immediate justification for believing that there is a material hand. For the dogmatist, this can be the case only if when you have $O$, you have the feeling of ascertaining the truth of the proposition that there is a material hand. Since when you have $O$ you have the experience as if there is something that is among other things material, via (DOGMA*), $O$ gives you immediate prima facie justification for believing $W$.

Consider now that since immediate justification is not based on independent justification for anything else, it is intuitively implausible that your immediate justification from $O$ for $W$ could exist in virtue of, among other things, the justification that $O$ gives you for $H$. More concretely, consider that if your immediate justification from $O$ for $W$ existed just in virtue of your justification from $O$ for $H$, it would presumably be true that hadn't you had justification from $O$ for $H$, you wouldn't have had justification for $W$. But this counterfactual appears false. Take for instance a closest possible world (to the imagined actual one) in which, as you see a hand, a trustworthy friend tells you that it is just a plastic-replica. Your justification from $O$ for $H$ is destroyed, but the fact that you can have the feeling of ascertaining the truth of $W$ still gives you immediate justification for believing $W$. Thus your immediate justification from $O$ for $W$ counts as direct justification for $W$.

In conclusion, if dogmatism is true, (MOORE) fulfils (FAIL2) with respect to $O$. The dogmatist can maintain, accordingly, that Moore's proof is epistemically flawed because it cannot transmit to $W$ your justification for $H$ depending on $O$, since $O$ gives you direct justification for $W$. This preempts the criticism that the dogmatist is committed to an intuitively flawed argument without undermining the dogmatist's ability to rebut (SCEPTIC).

\section{Acknowledgments}

I'm grateful to Lorenzo Casini, Tommaso Piazza, Karim Thebault and an anonymous reviewer of this Journal for comments on drafts of this paper. I'm also grateful to the Munich Center for 
Mathematical Philosophy (MCMP) and the Von Humboldt Foundation for supporting my research through a Visiting Fellowship at the MCMP.

\section{References}

Moore, G. E. 1939. Proof of an External World. Proceedings of the British Academy 25: 273-300.

Moretti, L. and Piazza, T. 2013. Transmission of Justification and Warrant. In E. N. Zalta (ed.), The Stanford Encyclopedia of Philosophy (Winter Edition).

http://plato.stanford.edu/archives/win2013/entries/transmission-justification-warrant/.

Pryor, J. 2000. The Skeptic and the Dogmatist. Nous 34: 517-549.

Pryor, J. 2004. What's wrong with Moore's argument? Philosophical Issue, 14, Epistemology: 349378.

Silins, N. 2007. Basic Justification and the Moorean Response to the Skeptic. In T. S. Gendler and J. Hawthorne (eds.), Oxford Studies in Epistemology, Vol. 2, 108-140. Oxford: OUP.

Wright, C. 2002. (Anti-)Sceptics Simple and Subtle: G. E. Moore and John McDowell. Philosophy and Phenomenological Research 65: 330-348.

Wright, C. 2003. Some Reflections on the Acquisition of Warrant by Inference. In S. Nuccetelli (ed.), New Essays on Semantic Externalism and Self-Knowledge, 57-77. Cambridge, Mass.: MIT Press. 